\title{
Small rodents - permanent reservoirs of toxocarosis in different habitats of Slovakia
}

\author{
K. REITEROVÁ ${ }^{1 *}$, D. ANTOLOVÁ ${ }^{1}$, G. ZALEŚNY $^{3}$, M. STANKO $^{1,2}$, S. ŠPILOVSKÁ ${ }^{1}$, L. MOŠANSKÝ $^{1}$
}

\begin{abstract}
${ }^{1}$ Institute of Parasitology of the Slovak Academy of Science, Košice, Hlinkova 3, 04001 Košice, Slovak Republic, Email: reiter@saske.sk, ${ }^{2}$ Institute of Zoology of the Slovak Academy of Science, Košice, Löfflerova 10, 04001 Košice, Slovak Republic; ${ }^{3}$ Department of Invertebrate Systematics and Ecology, Institute of Biology, Wroclaw University of Environmental and Life Sciences, Kozuchowska 5b, Wroclaw, Poland
\end{abstract}

\begin{abstract}
Summary
The study aimed to estimate the role of small rodents in the circulation of larval toxocarosis in light of their different habitats. From 2005 to 2008 , a total of 1523 small rodents, belonging to 11 species, were captured in 5 different habitats of Slovakia. Anti-Toxocara antibodies were detected in $6.6 \%$ animals. The dominant reservoirs of toxocarosis were striped-field mouse Apodemus agrarius (11.7\%) and mound-building mouse Mus spicilegus (10.7\%), while the seropositivity of voles was low. Sexually active adults were infected more frequently $(10.8 \%)$ in comparison with inactive ones $(5.2 \%)$. According to habitats, seroprevalence of toxocarosis in windbreaks $(2.4 \%)$ was significantly lower $(\mathrm{p}<0.05)$ than in agrocoenoses $(6.7 \%)$, alluvia $(8.5 \%)$ and ecotones $(7.5 \%)$. Log-linear analysis performed in A. agrarius indicates that type of habitat and sexual activity affect the seropositivity to Toxocara infection. The highest seroprevalence was observed in alluvium $(21.2 \%)$ while the lowest in windbreak $(1.8 \%)\left(\chi^{2}=\right.$ $17.232, \mathrm{p}<0.001)$ and sexually active mice were characterised by $22.5 \%$ and sexually inactive by $6.4 \%$ seroprevalence $\left(\chi^{2}=30.634, p<0.001\right)$. The occurrence pattern of toxocarosis in small rodents suggests that they are permanent reservoirs for Toxocara spp. in nature and significant indicators of Toxocara egg contamination in environs.
\end{abstract}

Keywords: Toxocara spp.; small rodents; reservoir; habitat

\section{Introduction}

Toxocara canis and Toxocara cati are important nematode parasites, commonly found in carnivores but able to invade a wide range of other hosts, including humans (Glickman \& Magnaval, 1993; Okulewicz, et al., 2012), what has caught the attention of the medical and veterinary scientific community. Toxocara spp. is distributed in all places where climatic conditions allow the completion of the life cycle. Infected domestic and wild carnivores shed the eggs to the environment. Within a period of three weeks to several months (depending on climatic conditions and soil type) the eggs embryonate and serve as a source of infection for both definitive and paratenic hosts. Humans become infected by ingesting viable embryonated eggs.

The seroprevalence of human larval toxocarosis varies in different parts of the world, ranging between $2-5 \%$ in urban and $14.2-37 \%$ in rural areas in west European countries to as much as $86 \%$ in some tropical areas of the world (Sadjjadi et al., 2000; Despommier, 2003; Habluetzel et al., 2003; Deutz et al., 2005; Díez-Morrondo et al., 2010). In Slovakia, Havasiová et al. (1993) stated $13.7 \%$ seroprevalence in healthy human population and in recent study Pavlinová et al. (2011) reported $5.5 \%$ seropositivity to Toxocara in women with habitual abortions.

Small mammals, paratenic hosts, play a significant role in the circulation of toxocarosis, as the larvae can survive in their tissue for a long time. They present an important reservoir of infection for both free-living and domestic carnivores. In terms of epidemiology, the most important fact is that the larvae from the paratenic hosts develop directly into adult worms in the intestinal tract of the definitive hosts and then contaminate the environment with the eggs. Public places contaminated with Toxocara spp. eggs, particularly parks, children playgrounds and sandpits pose a threat of infection for humans and most notably children (Havasiová et al., 1993; Reiterová et al., 2004). To assess the epidemiological associations and infection risk for humans it is necessary to map in detail its occurrence in definitive and paratenic hosts and clarify its circulation in the natural ecosystems.

The aim of this work was to estimate the seroprevalence of larval toxocarosis in small mammals from different habitats of Eastern and Central Slovakia and analyse the factors influencing the infection rate. 


\section{Materials and methods}

\section{Study area}

Between the years 2005 and 2008 continuous teriological and epidemiological survey focused on the influence of environmental conditions in different habitats on the occurrence of toxocarosis in small mammals. To obtain comprehensive picture of the role of different conditions in the circulation and spread of Toxocara spp., the research was conducted in 31 different localities of Slovakia. Localities with similar environmental specifications and characteristics were divided into five groups, representing five different habitats. Cultivated ecosystems, the basic functions (first of all, productivity) of which are maintained by a system of agronomical measures were classified as agrocoenoses. The term ecotone was used for transition areas between two adjacent ecological communities, in this instance forest and agrocoenoses. One, two or more rows of poplars in agrocoenosis serving to lessen or break the force of the wind were classified as windbreak. Small mammals trapped along rivers and brooks and in shrubs on river banks came from alluvium. Urban small mammals are those trapped in buildings, granaries and courtyards.

\section{Sampling}

A total of 1523 free-living small mammals were trapped during 2005 - 2008 in different localities in Eastern and Central Slovakia. They were caught in standard live and snap traps set in lines. Wicks soaked in an oil and nut mixture were used as baits. The traps were placed $5 \mathrm{~m}$ apart from each other. According to locality conditions, one to three trap lines (50 traps/line) were usually exposed for one or two nights (Stanko et al. 2004). During the study together 8700 traps were exposed (agrocoenoses - 2900 traps; alluvia - 2000 traps; ecotones - 1500 traps; windbreaks - 2000 traps; urban -300 traps). Proportionality of the exposed traps was as follow, $46.6 \%$ in $2005 ; 23.6 \%$ in $2006 ; 17.2 \% 2007$ and $12.6 \%$ in 2008. The trap lines were checked regularly in the morning. The protected species of small mammals (except dead ones) were released back to nature. The captured animals were narcotized in laboratory conditions, and examined by standard zoological and parasitological methods.

Animals were divided into subadults and adults according to Pelikán (1965). Adult individuals were either sexually active or inactive ones that had already been sexually active previously. Small individuals showing no signs of sexual activity that had not yet reached sexual maturity were classified as subadults. Individuals with distinctly larger testes and glandulae vesiculares were characterised as sexually active males. Sexually active females were those with a vaginal plug, corpora lutea, pregnant or lactating. Adult, but sexually inactive individuals were males with testes in regression and females with placental scars.

The animals' hearts with their blood clot were cut open, eluted in $1 \mathrm{ml}$ of saline solution for 24 hours and then centrifuged at $500 \mathrm{~g}$ for 2 min (Treml \& Nesňálová, 1993) and the supernatant fraction (further referred to as the eluate) was subsequently used for serological examination.

\section{Determination of anti-Toxocara antibodies using indirect} ELISA

T. canis larval excretory-secretory antigen $(\mathrm{E} / \mathrm{S} \mathrm{Ag})$ was prepared according to de Savigny (1975). The antigen has been tested to be specific, without cross-reactions with sera of mice experimentally infected with Toxascaris leonina and Ascaris suum (Cuéllar et al., 1995). The sensitivity of the antigen validated Reperant et al. (2009) on sera of Microtus arvalis experimentally infected with $T$. canis. Anti-Toxocara antibodies in the heart eluates of small mammals were determined using ELISA modified by Havasiová-Reiterová et al. (1995) who confirmed the correlation between specific antibody production and infective doses of five or seven $T$. canis and $T$. cati eggs, respectively. Microtitre plates were coated overnight at $4{ }^{\circ} \mathrm{C}$ with $T$. canis larval excretory-secretory antigen containing 1.25 $\mu \mathrm{g} / \mathrm{ml}$ protein diluted in carbonate buffer, $\mathrm{pH}$ 9.6. The plates were washed three times with phosphate buffer saline $\mathrm{pH} 7.2$ containing Tween 20 (PBS-T20). The eluates (diluted $1: 2$ in $5 \%$ skimmed milk in PBS-T20) were placed to plates in a volume $100 \mu \mathrm{l}$ per well. After $1 \mathrm{~h}$ incubation at $37^{\circ} \mathrm{C}$ the plates were repeatedly washed 3 times. Horse-radish peroxidase-labelled anti-mouse immunoglobulin (Anti-mouse Polyvalent Immunoglobulins IgG, IgA, IgM; Sigma-Aldrich Chemie GmbH, Steinheim, Germany) diluted 1: 8000 in a volume of $100 \mu$ was used as conjugate. After incubation for $1 \mathrm{~h}$ plates were washed 3 times and $100 \mu \mathrm{l}$ of substrate (o-phenylenediamin with $0.05 \% \mathrm{H}_{2} \mathrm{O}_{2}$ ) was added. The reaction was stopped after $20 \mathrm{~min}$ of incubation in the dark at the room temperature by $50 \mu \mathrm{l}$ of $2 \mathrm{M} \mathrm{H}_{2} \mathrm{SO}_{4}$ and the optical density was measured spectrophotometrically at $490 \mathrm{~nm}$ (Thermo Labsystems Opsys MR, Chantily, Virginia, USA).

Positive sera of mice experimentally infected with $T$. canis and sera of helminth-free mice were used as positive and negative controls, respectively.

\section{Data analysis}

The prevalence of anti-Toxocara antibodies was calculated in the examined population of small mammals. In the case of 1373 rodents (out of 1523) we possess complete database including all information regarding host species, host age and sex, sexual activity of rodents and year of sampling. Those data were included to logistic regression analysis and odds ratio (OR), a measure of the effect size, describing the strength of association or independence between two binary data values, was calculated to estimate the association between variables included in the study. At the beginning, we put all factors to the analysis and using backward methods we have obtained minimal adequate model explaining the relationships between analysed variables. Due to large dataset and relatively small subsets, the interaction effects were not taken into consideration. Since the overall number of seropositive rodents was too low, i.e. 
only in few species prevalence exceed $10 \%$, the detailed statistical analysis of factors affecting the presence of Toxocara spp. was conducted for two species Apodemus agrarius and Mus spicilegus. We have investigated if the presence of anti-Toxocara antibodies is affected by intrinsic and extrinsic factors. Calculations were performed by the use of general log-linear analysis of contingency tables. In the case of $A$. agrarius following factors were included to the model: seropositivity (0/1), gender (male/female), sexual activity (0/1) (host age was excluded from the analysis due to the fact that all sexually inactive rodents were classified as subadult) and type of habitat (agrocoenoses/alluvium/ecotone/windbreak/urban). Whereas $M$. spicilegus was reported mainly in agrocoenoses, only three factors were included to beginning model, i.e. seropositivity (0/1), gender (male/female) and sexual activity (0/1). As a result of log-linear analysis minimum sufficient model was generated where chi-square value was not significant, indicating that the model was adequate in explaining the data (Abu-Madi et al., 1998; Behnke et al., 1999). All statistical analyses were conducted using STATISTICA ver. 10.0 (StatSoft, Inc.).

\section{Results}

Totally 1523 specimens of free-living small rodents were examined within the period of 2005 - 2008. Examined material comprised the following 11 species: Cricetus cricetus (Linnaeus, 1758) - common hamster, Myodes (Clethrionomys) glareolus (Schreber, 1780) - bank vole, Microtus arvalis (Pallas, 1779) - common vole, Microtus subterraneus (de Sélys-Longchamps, 1836) - common pine vole, Micromys minutus (Pallas, 1771) - harvest mouse, Apodemus sylvaticus (Linnaeus, 1758) - wood mouse, Apodemus flavicollis (Melchior, 1834) - yellownecked mouse, Apodemus microps Kratochvíl et Rosický, 1952 - pygmy field mouse, Apodemus agrarius (Pallas,
1711) - striped field mouse, Mus musculus Linnaeus, 1758 - eastern house mouse and Mus spicilegus (Petényi, 1882) - mound-building mouse.

The most dominant rodent species was Apodemus agrarius (41.0\%). Other recorded dominant species were Apodemus flavicollis (17.1 \%), Microtus arvalis (12.3\%), Myodes (C.) glareolus $(11.1 \%)$ and Mus spicilegus $(10.2 \%)$. The proportion of members of the Microtidae family was 23.7\% (four species) and Muridae family $73.1 \%$ (seven species).

Out of 1523 examined small rodents, specific antibodies were serologically confirmed in 100 individuals of seven species, i.e. $6.6 \%$ mean seropositivity (Table 1). The highest relative density of small mammals, expressed as the mean number of animals captured per 100 traps, was recorded in 2007 with 23.3 individuals and the lowest with 14.7 specimens in 2005 , but the relative density of small mammals did not correlate with the toxocarosis prevalence rates in individual years.

During monitored period the highest seropositivity (9.5\%) was found in 2006, but in the next two years decreased to less than half as the maximum (Fig. 1). However the year of sampling was not fit to the minimal adequate model of logistic regression $\left(\mathrm{p}<0.797 ; \chi^{2}=0.066 ;\right.$ OR $=0.968$ [95 \% C.I: $0.757-1.238]$ ). Another factor, host species, affects the prevalence of anti-Toxocara antibodies significantly $\left(\mathrm{p}<0.022 ; \chi^{2}=5.229 ;\right.$ OR $=0.880$ [95\% C.I: 0.788 $-0.982])$. The highest positivity was found in the predominant species Apodemus agrarius (11.7\%) and other murid rodents, Mus spicilegus (10.7\%) and Mus musculus (5.0\%). In $A$. flavicollis, the second most numerous species, only $1.5 \%$ prevalence of antibodies was observed. In other, less numerous species, toxocarosis was detected less frequently or not at all (Table 1). The age did not influence the positivity of small rodents significantly $\left(\mathrm{p}=0.651 ; \chi^{2}=\right.$ $0.204 ; \mathrm{OR}=1.183$ [95\% C.I: $0.569-2.448]$ ), despite the fact that more than twofold value of mean seropositivity

Table 1. Anti-Toxocara antibodies in heart eluates of different species of small rodents captured between 2005 and 2008

\begin{tabular}{lccccccc}
\hline \multirow{2}{*}{ Species } & \multicolumn{4}{c}{ Years } & $\mathrm{n} / \mathrm{N}$ & \multicolumn{3}{c}{ Total } \\
\cline { 2 - 7 } & 2005 & 2006 & 2007 & 2008 & $\mathrm{n} / \mathrm{N}$ & $\%$ & $95 \%$ CI \\
\hline Cricetus cricetus & $0 / 2$ & $0 / 1$ & - & - & $0 / 3$ & 0.0 & - \\
Myodes glareolus & $3 / 61$ & $0 / 23$ & $0 / 51$ & $1 / 35$ & $4 / 170$ & 2.4 & $0.33-7.1$ \\
Microtus arvalis & $0 / 146$ & $0 / 32$ & $0 / 9$ & $0 / 1$ & $0 / 188$ & 0.0 & - \\
Microtus subterraneus & $0 / 3$ & $0 / 3$ & $0 / 2$ & - & $0 / 8$ & 0.0 & - \\
Micromys minutus & $0 / 7$ & $0 / 11$ & $0 / 4$ & - & $0 / 22$ & 0.0 & - \\
Apodemus sylvaticus & $0 / 2$ & $0 / 1$ & - & - & $0 / 3$ & 0.0 & - \\
Apodemus flavicollis & $0 / 47$ & $4 / 101$ & $0 / 75$ & $0 / 37$ & $4 / 260$ & 1.5 & $0.53-3.5$ \\
Apodemus microps & $0 / 31$ & $1 / 15$ & $0 / 19$ & $0 / 4$ & $1 / 69$ & 1.4 & $-0.3-8.0$ \\
Apodemus agrarius & $23 / 229$ & $30 / 160$ & $13 / 162$ & $7 / 74$ & $73 / 625$ & 11.7 & $9.6-14.1$ \\
Mus musculus & $0 / 3$ & $1 / 2$ & $0 / 3$ & $0 / 12$ & $1 / 20$ & 5.0 & $0.3-14.4$ \\
Mus spicilegus & $15 / 66$ & $2 / 51$ & $0 / 25$ & $0 / 13$ & $17 / 155$ & 10.7 & $6.4-17.6$ \\
\hline Total & $41 / 597$ & $38 / 400$ & $13 / 350$ & $8 / 176$ & $100 / 1523$ & 6.6 & $5.4-7.9$ \\
\hline $\mathrm{n}-$ number of positive; $\mathrm{N}-$ number of animals examined, $\%$ - seropositivity & & &
\end{tabular}




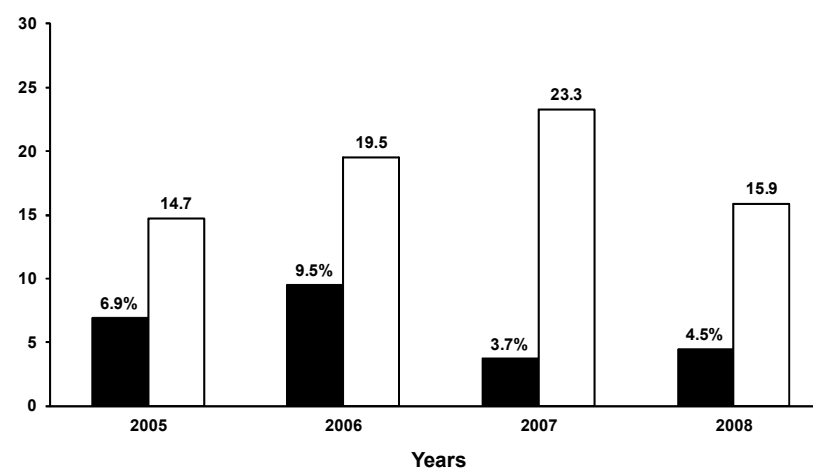

Fig. 1. Seropositivity to Toxocara spp. and the relative density of small rodents captured in different habitats between $2005-2008$ - seropositivity of small rodents (\%); $\square$ mean number of animals captured per 100 traps

was found in adult small rodents when compared to that in subadults $(9.8 \%$ and $4.4 \%$, respectively) (Table 2$)$. Analyses of gender-related levels of anti-Toxocara antibodies demonstrated small discrepancies $\left(\mathrm{p}=0.471 ; \chi^{2}=0.519\right.$; $\mathrm{OR}=1.181 \quad[95 \%$ C.I: $0.744-1.813]$ ), although mean

Table 2. Anti-Toxocara antibodies in heart eluates of different species of small rodents captured between 2005 and 2008, relative to host age and gender of animals

\begin{tabular}{lccc}
\hline Category & $\mathrm{n} / \mathrm{N}(\%)$ & $95 \% \mathrm{CI}$ & $\mathrm{OR}$ \\
\hline Age & & & \\
Subadult & $37 / 832(4.4)$ & $3.0-6.5$ & \\
Adult & $63 / 643(9.8)$ & $7.8-12.1$ & 1.183 \\
\hline Gender & & & \\
Male & $42 / 761(5.5)$ & $3.9-7.6$ & 1.181 \\
Female & $58 / 728(8.0)$ & $6.2-10.2$ & \\
\hline \multicolumn{4}{c}{$\mathrm{n}$ - number of positive; N-number of animals examined, } \\
\multicolumn{4}{c}{$\%$ - seropositivity }
\end{tabular}

seroprevalence in females was higher $(8.0 \%)$ than in males $(5.5 \%)$ the differences were not significant (Table 2). On the other hand, sexual activity seems to be a major factor influencing infection risk $\left(\mathrm{p}<0.001 ; \chi^{2}=16.712\right.$; OR $=$ 2.537 [95\% C.I: 1.623 - 3.963]), sexually active animals were infected more frequently $(10.8 \%)$ than inactive ones $(5.2 \%)$ (Table 3$)$. Examined small rodents came from five different habitat types. The lowest occurrence of antibodies was recorded in animals trapped in windbreaks $(2.4 \%)$, while in other habitats the seroprevalence ranged between $5.9 \%$ and $8.5 \%$ (Table 4$)\left(\mathrm{p}=0.007 ; \chi^{2}=7.391 ; \mathrm{OR}=\right.$ 0.772 [95\% C.I: $0.640-0.930])$.

The long-linear analyses of contingency tables were performed for two species only. In the case of A. agrarius following model was obtained: seropositivity/habitat/sexual activity; gender/habitat; sexual activity/gender $\left(\chi^{2}=9.802 ; p=0.776\right)$. The results indicate that two factors, i.e. type of habitat and sexual activity, affect seroprevalence of Toxocara infection. The highest seroprevalence was observed in alluvium $-21.2 \%$ while the lowest in windbreak $-1.8 \%\left(\chi^{2}=17.232, \mathrm{p}<0.001\right)$. Sexually active mice were characterized by 3.5 times higher value of seroprevalence than sexually inactive $\left(22.5 \%\right.$ vs. $\left.6.4 \% ; \chi^{2}=30.634, p<0.001\right)$. Since the vast majority of M. spicilegus (146 out of 155) were sampled in agrocoenoses it was impossible to put the type of habitat as a variable in log-linear analysis. Therefore, in case of mound-building mice seroprevalence of Toxocara spp. was analysed in relation to two factors i.e. hosts gender and sexual activity. We obtained the following model describing interaction between analysed variables: seropositivity/sexual activity/gender $\left(\chi^{2}=5.559 ; \mathrm{p}=0.352\right)$, thus, the prevalence of anti-Toxocara antibodies seem not to be affected by analysed factors.

\section{Discussion}

Larval toxocariasis, circulating in sylvatic and synanthropic cycle, belongs to global zoonoses and poses the permanent human health risk (Despommier, 2003). The study focused on the role of small rodents, reservoirs of infection for domestic and wild carnivores, in the spread of the disease in different habitats.

Presented results revealed differences between seropositivity to Toxocara in individual rodent species. Food factors (eating earthworms and insect larvae that may serve as carriers of Toxocara eggs) (Thyssen et al., 2004) and the ecology of the small mammal species may account for the higher prevalence rates detected in several species of small rodents. The preference of wet habitats may be another reason of higher seropositivity to Toxocara, as the eggs have a better survival rate there. Wet habitat is predominantly preferred by $A$. agrarius (Zejda, 1967), in which the

Table 3. Anti-Toxocara antibodies in heart eluates of sexually active and inactive small rodents captured between 2005 and 2008

\begin{tabular}{|c|c|c|c|c|}
\hline \multirow{3}{*}{ Category } & Males & Females & Tota & \\
\hline & $\mathrm{n} / \mathrm{N}(\%)$ & $\mathrm{n} / \mathrm{N}(\%)$ & $\mathrm{n} / \mathrm{N}(\%)$ & \multirow{2}{*}{ OR } \\
\hline & $(95 \% \mathrm{CI})$ & $(95 \% \mathrm{CI})$ & $(95 \%$ CI $)$ & \\
\hline Sexually & $16 / 164(9.8)$ & $23 / 196(11.7)$ & 39 / $360(10.8)$ & \multirow{4}{*}{2.537} \\
\hline active & $(5.5-16.3)$ & $(6.6-19.5)$ & $(7.6-15.0)$ & \\
\hline Sexually & $6 / 148(4.1)$ & 4 / $43(3.3)$ & $10 / 191(5.2)$ & \\
\hline inactive & $(1.4-9.1)$ & $(2.5-24.0)$ & $(1.9-11.4)$ & \\
\hline
\end{tabular}


Table 4. Anti-Toxocara antibodies in heart eluates of small rodents captured in different habitat types between 2005 and 2008

\begin{tabular}{lcccc}
\hline Habitats & $\mathrm{N}$ & $\mathrm{n}$ & $\begin{array}{c}\text { Seropositivity } \\
(\%)\end{array}$ & $95 \% \mathrm{CI}$ \\
\hline Agrocoenoses & 431 & 29 & 6.7 & $4.1-10.7$ \\
Alluvium & 200 & 17 & 8.5 & $5.7-13.9$ \\
Ecotone & 625 & 47 & 7.5 & $5.8-9.6$ \\
Windbreak & 250 & 6 & 2.4 & $1.1-4.5$ \\
Urban & 17 & 1 & 5.9 & $0.3-28.7$ \\
\hline \multicolumn{4}{c}{$\mathrm{N}$ - number of animals examined; $\mathrm{n}$ - number of positive }
\end{tabular}

highest prevalence of antibodies was recorded. Mus spicilegus, species with the second highest seropositivity in the survey, is frequent in lowlands of east and west Slovakia. In autumn and winter whole families live together in the nests below storage mounds, the community often consists of 6 to 21 individuals (Čanády et al., 2009). Foxes and other carnivores prey on them, often leaving faeces on the top of mice mounds. The faeces are dissolved by rain and Toxocara eggs are washed into lower mound layers, thus presenting a risk of infection. Randomly found red fox faeces collected directly from the mounds of $M$. spicilegus and examined coprologically were positive for the Toxocara spp. eggs, verifying this assumption. Even though the number of examined samples is not significant, it refers to the permanent circulation of toxocarosis in monitored habitats. Miterpáková et al. (2009) determined 12.5 - $13 \%$ prevalence of $T$. canis in red foxes from localities where small rodents were trapped.

Prevalence of larval toxocarosis in paratenic hosts was not found to be significantly influenced by the population age, however two times higher prevalence of infection in adults than in subadults suggests that probability of infection with roundworm eggs from contaminated environment increases with the exposure time. On the other hand, with regard to lower seropositivity of young animals, transplacental and lactogenic transmission (Tomašovičová et al., 1993; Reiterová et al., 2003; 2006) of larvae from infected mothers to their offspring seem to be less frequent, however considering a high reproduction capacity of rodent species, not neglectable.

Another factor influencing positivity of small rodents was sexual activity of adult animals. We suppose, that pregnancy and lactation of sexually active females and enhanced energy losses in males looking for the females in mating season leads to ingestion of higher food quantities, potentiating the probability of infection. Moreover, adult animals have a larger home range than immature ones (Vukičevič-Radič et al., 2006), therefore moving to a larger area are more likely to be infected by Toxocara eggs.

When evaluating the seropositivity in different habitats, significantly higher prevalence was recorded in the alluvia of streams and rivers, ecotons between forests and fields and in agrocoenoses in comparison with values obtained in windbreaks. This may be due to a better survival rate of Toxocara eggs in soil, or a higher number of reservoir animals found in some habitats. Blaszkowska et al. (2011) detected Toxocara eggs in soil samples from three out of five examined field localities, confirming that agrocenoses are possible source of the infection.

In Slovakia the first research of larval toxocarosis in small mammals was carried out in 1991 - 1993 in localities with different anthropogenic pressure. Anti-Toxocara antibodies were detected in $15.1 \%$ of synanthropic and hemisynanthropic species: house mouse (Mus musculus) in $32.0 \%$, striped-field mouse (A. agrarius) in $30.4 \%$ and harvest mouse (Micromys minutus) in $25.0 \%$ (Dubinský et al., 1995). Within another survey in $2000-2004$, out of 2140 serologically examined heart eluates of small mammals anti-Toxocara antibodies were recorded in $6.4 \%$ individuals, with $A$. agrarius ( $10.9 \%$ ) being predominantly responsible for maintaining the infection (Antolová et al., 2013). Similarly, in our study the most important reservoirs seem to be A. agrarius and Mus spicilegus. Their zoonotic potential has resulted from their aetiology and ecology. During autumn, A. agrarius tends to overpopulate and spreads into city edges and vicinity of human settlements (Sládek and Mošanský, 1985), presenting a risk of infection for domestic carnivores and subsequently increasing infection hazard to humans. Mus spicilegus, living in numerous communities through autumn and spring, attracts mainly foxes, which regularly mark the mounds with faeces. Sylvatic circulation of toxocarosis includes common forest rodents Myodes glareolus (2.4\%) and A. flavicollis (1.5 $\%)$ that serve as important reservoirs for wild carnivores. Recently, Reperant et al. (2009) emphasized the role of rodents as indicators of zoonotic parasites in carnivores in urban ecosystem. They play an influential role of intermediate and paratenic host and serve as valuable indicators for assessing occurrence and degree of environmental contamination and subsequent infection pressure to humans. In Switzerland, in the Canton of Geneva, the highest incidence of Toxocara spp. infection in urban ecosystem $(13.2 \%)$ correlated with a higher occurrence of domestic carnivores and red foxes in aforementioned localities (Reperant et al., 2009). In Poland, examination of brains and livers of $31 \mathrm{~A}$. agrarius individuals from the recreational area of Wroclaw revealed the presence of migratory Toxocara spp. larvae in four animals (12.9\%). The data refer to the role of rodents in the spread of toxocarosis in the suburban and tourist area (Hildebrand et al., 2009).

In conclusion, the study highlights the important role of small rodents in permanent maintenance of the parasite particularly in alluvia, ecotones of forests and in agrocoenoses. Presence of specific antibodies in small rodents during four years signalises long-lasting occurrence of the disease in monitored habitats with fluctuation in different years. The significant factor influencing the risk of infection seems to be the sexual activity and the age of animals. Dynamics of population density of small mammals in individual years depends on climatic and trophic factors, thus altering toxocarosis prevalence in definitive hosts and consequent environmental contamination. Determining the degree of Toxocara infection in free-living small rodents in 
natural ecosystems will help to clarify the circulation of this zoonotic infection in nature and will become the basis for better understanding of the epidemiological situation in the monitored regions.

\section{Acknowledgement}

The publication has been realized within a frame of the project Centre of Excellence for Parasitology (Code ITMS: 26220120022) based on the support of the Operational Programme 'Research \& Development' funded from the European Regional Development Fund (0.5) and partially financed by the Slovak Research and Development Agency under the contracts No. APVV-0267-10 and VEGA No. 2/0137/10.

The present study complies with all current laws governing research in Slovakia. Capture, handling and care of mammals complied with all relevant laws of the Slovak Republic.

\section{References}

Abu-Madi, M. A., BehnKe, J. M., Lewis, J. W., Gilbert, F. S. (1998): Descriptive epidemiology of Heligmosomoides polygyrus in Apodemus sylvaticus from three contrasting habitats in south-east England. J. Helminthology 72: $93-100$

\section{DOI: $10.1017 / \mathrm{S} 0022149 \mathrm{X} 00016254$}

Antolová, D., Reiterová, K., Stanko, M., Zalesny, G., FričovÁ, J., DVOroŽŇÁKOVÁ E. (2012): Small mammals: paratenic hosts for species of Toxocara in eastern Slovakia. J. Helminthol., 87: 52 - 58. DOI: 10.1017/S0022149X11000848

BeHnKe, J. M., LeWIS, J. W., MoHD-Zain, S. N., GILBERT, F. S. (1999): Helminth infections in Apodemus sylvaticus in southern England: interactive effects of host age, sex and year on the prevalence and abundance of infections. $J$. Helminthol., 73: $31-44$

Blaszkowska, J., Kurnatowski, P., Damiecka, P. (2011): Contamination of the soil by eggs of geohelminths in rural areas of Lodz district (Poland). Helminthologia, 48: 67 - 76. DOI: 10.2478/s11687-0110012-8

ČAnÁDY, A., MošAnSKÝ, L., STANKO, M. (2009): The first knowledge of winter ecology of the mound-building mouse (Mus spicilegus Petényi, 1882) from Slovakia. Acta Zool. Bulgarica, 61: $79-86$

CuÉllar, C., Fenoy, S., Guillén, J. L. (1995): Crossreactions of sera from Toxascaris leonina and Ascaris suum infected mice with Toxocara canis, Toxascaris leonina and Ascaris suum antigens. Int. J. Parasitol., 25: $731-739$

DE SAVIGNY, D. H. (1975): In vitro maintenance of Toxocara canis larvae and a simple method for the production of Toxocara ES antigen for use in serological tests for visceral larva migrans. J. Parasitol., 61: 781 - 782

DESPOMMIER, D. (2003): Toxocariasis: clinical aspects, epidemiology, medical ecology, and molecular aspects. Clin. Microbiol. Rev., 16: 265 - 272
Deutz, A., Fusch, K., Auer, H., Kerb, U., AspöcK, H., KÖFER, J. (2005): Toxocara-infestation in Austria: a study on the risk of infection of farmers, slaughterhouse staff, hunters and veterinarians. Parasitol. Res., 97. 390 - 394. DOI: $10.1007 / \mathrm{s} 00436-005-1469-5$

Díez-Morrondo, C., SÁnchez-Andrade, R., Ibastea, P., Arias, M. S., SÁnchez-Andrade, A., SuÁrez, J. L., Francisco, I., Romasanta, A., Morrondo, P., DietBanos, P., PAZ-Silva, A. (2010): A case-control study to analyze the influence of the environment in human sensitization against helminth parasitic antigens. Rev. Ibero-Latinoam. Parasitol., 69: $38-44$

Dubinský, P., Havasiová-Reiterová, K., PeŤKo, B., HovOrKA, I., TOMAŠOVIČOVÁ, O. (1995): Role of small mammals in the epidemiology of toxocariasis. Parasitology, $110: 187-193$

Glickman, L. T., Magnaval, J. F. (1993): Zoonotic roundworm infections. Inf. Dis. North Am., 7: 717 - 732.

Habluetzel, A., Traldi, G., Ruggieri, S., Attili, A.R., Scuppa, P., Marchetti, R. Menghini, G., Esposito, F. (2003): An estimation of Toxocara canis prevalence in dogs, environmental egg contamination and risk of human infection in the Marche region of Italy. Vet. Parasitol., 113: $243-252$

HAVASIOVÁ, K., DubinskÝ, P., ŠTeFAnČíKovÁ, A. (1993): A seroepidemiological study of human Toxocara infection in the Slovak Republic. J. Helminthol., 67: $291-296$

HAVASIOVÁ-REITEROVÁ, K., TOMAŠOVIČOVÁ, O., DUBINSKÝ, P. (1995): Effect of various doses of infective Toxocara canis and Toxocara cati eggs of the humoral response and distribution of larvae in mice. Parasitol. Res., 81: $13-17$

Hildebrand, J., Zalesny, G., OKulewicz, A., BASZKIEWICZ, K. (2009): Preliminary studies on the zoonotic importance of rodents as a reservoir of toxocariasis from recreation grounds in Wroclaw (Poland). Helminthologia 46, 80-84. DOI: 10.2478/s11687-009-0016-9

MiterpákovÁ, M., HurníkovÁ, Z., AntolovÁ, D., DUBINSKÝ, P. (2009): Endoparasites of red fox (Vulpes vulpes) in the Slovak Republic with the emphasis on zoonotic species Echinococcus multilocularis and Trichinella spp. Helminthologia, 46: 73 - 79. DOI: 10.2478/s11687009-0015-x

OKulewicz, A., Perec-Matysiak, A., Buńkowska, K., Hildebrand, J. (2012): Toxocara canis, Toxocara cati and Toxascaris leonina in wild and domestic carnivores. Helminthologia, 49: 3 - 10. DOI: 10.2478/s11687-0120001-6

Pavlinová, J., KinčeKová J., Ostró, A., SAKsun, L., VASILKOVÁ, Z., KÖNIGOVÁ, A. (2011): Parasitic infections and pregnancy complications. Helminthologia 48: 8 - 12 . DOI: $10.2478 / \mathrm{s} 11687-011-0002-\mathrm{x}$

PELIKÁN, J. (1965): Reproduction, population structure and elimination of males in Apodemus agrarius (Pall.). Zoologické listy, 14: 317 - 332

ReiterovÁ, K., HalÁsová, D., MiterpákovÁ, M., KinČeková, J., Juriš, P., Stanko, M., DubinskÝ, P. (2004): Circulation of toxocarosis in countryside and ha- 
zard of its transmission. Slovak Vet. Journal, 29: 34 - 36. (In Slovak)

REITEROVÁ, K., TOMAŠOVIČOVÁ, O., DUBINSKÝ, P. (2003): Influence of maternal infection on offspring immune response in murine larval toxocariasis. Parasite Immunol., 25: $361-368$.

REITEROVÁ, K., TOMAŠOVIČOVÁ, O., DUBINSKÝ, P. (2006): Influence of Toxocara canis infection during pregnancy on offspring resistance towards re-infection. Parasitology, 132: $625-633$

Reperant, L.A., Hegglin, D., Tanner, I., Fischer, C., DEPlAZES, P. (2009): Rodents as shared indicators for zoonotic parasites of carnivores in urban environments. Parasitology, 136: $329-337$

SAdJjadi, S.M., Khorsravi, M., Mehrabani, D., Oryan, A. (2000): Seroprevalence of Toxocara infection in school children in Shiraz, Southern Iran. J. Trop. Pediatrics 46: $327-330$

SLÁDEK, J., MoŠANSKÝ, A. (1985): Mammals around us. 1st ed., Martin, Osveta, p. 247. (In Slovak)

StANKO, M., FriČOVÁ, J., SCHNIEREROVÁ, E., MoŠANSKÝ, L., MARDZINOVÁ, S. (2004): Fauna of small mammals
(Insectivora, Rodentia, Carnivora) around Rozhanovce (Košice basin). Natura Carpatica, 45: 107 - 116. (In Slovak) Thyssen, P. J., Moretti, T. C., Ueta, M. T., Ribeiro, O. B. (2004): O papel de insetos (Blattodea, Diptera e Hymenoptera) como possíveis vetores mecânicos de helmintos em ambiente domiciliary e peridomiciliar. Cad. Saúde Pública, 20: 1096 - 1102

TOMAŠOVIČOVÁ, O., HAVASIOVÁ-REITEROVÁ, K., DUBINSKÝ, P., HovORKA, I. (1993): Intrauterine and lactogenic transfer of Toxocara canis larvae in paratenic hosts. Helminthologia, 30: 111 - 113

TREML, F., NeSŇÁlOVÁ, E. (1993): Serological screening of the occurrence of antibodies to leptospires in free-living small mammals. Vet. Med., 38: $559-568$

VUKIČEVIČ-RADIČ O., MATIČ R., KATARANOVSKI D., STAMENKOVIČ S. (2006): Spatial organization and home range of Apodemus flavicollis and A. agrarius on Mt. Avala, Serbia. Acta Zool. Hung., 52: 81 - 96

ZEJDA, J. (1967): Habitat selection in Apodemus agrarius (Pallas, 1778) (Mammalia: Muridae) on the border of the area of its distribution. Zool. listy 16: 15 - 30. (In Slovak) 